\title{
Lungs donated after circulatory death and prolonged warm ischemia are transplanted successfully after enhanced ex vivo lung perfusion using adenosine A2B receptor antagonism
}

\author{
Eric J. Charles, MD, ${ }^{a}$ J. Hunter Mehaffey, MD, ${ }^{a}$ Ashish K. Sharma, MBBS, PhD, ${ }^{a}$ Yunge Zhao, MD, PhD, ${ }^{a}$ \\ Mark H. Stoler, MD, James M. Isbell, MD, MSCI, ${ }^{\mathrm{b}}$ Christine L. Lau, MD, MBA, ${ }^{\mathrm{a}}$ Curtis G. Tribble, MD, ${ }^{a}$ \\ Victor E. Laubach, $\mathrm{PhD},{ }^{\mathrm{a}}$ and Irving L. Kron, $\mathrm{MD}^{\mathrm{a}}$
}

\section{ABSTRACT}

Objective: The current supply of acceptable donor lungs is not sufficient for the number of patients awaiting transplantation. We hypothesized that ex vivo lung perfusion (EVLP) with targeted drug therapy would allow successful rehabilitation and transplantation of donation after circulatory death lungs exposed to 2 hours of warm ischemia.

Methods: Donor porcine lungs were procured after 2 hours of warm ischemia postcardiac arrest and subjected to 4 hours of cold preservation or EVLP. ATL802, an adenosine $A_{2 B}$ receptor antagonist, was administered to select groups. Four groups ( $\mathrm{n}=4$ /group) were randomized: cold preservation (Cold), cold preservation with ATL802 during reperfusion (Cold + ATL802), EVLP (EVLP), and EVLP with ATL802 during ex vivo perfusion (EVLP + ATL802). Lungs subsequently were transplanted, reperfused, and assessed by measuring dynamic lung compliance and oxygenation capacity.

Results: EVLP + ATL802 significantly improved dynamic lung compliance compared with EVLP $\left(25.0 \pm 1.8\right.$ vs $\left.17.0 \pm 2.4 \mathrm{~mL} / \mathrm{cmH}_{2} \mathrm{O}, P=.04\right)$, and compared with cold preservation (Cold: 12.2 $\pm 1.3, P=.004$; Cold + ATL802: $\left.10.6 \pm 2.0 \mathrm{~mL} / \mathrm{cmH}_{2} \mathrm{O}, P=.002\right)$. Oxygenation capacity was highest in EVLP (440.4 \pm 37.0 vs Cold: $174.0 \pm 61.3 \mathrm{~mm} \mathrm{Hg}, P=.037)$. No differences in oxygenation or pulmonary edema were observed between EVLP and EVLP + ATL802. A significant decrease in interleukin-12 expression in tissue and bronchoalveolar lavage was identified between groups EVLP and EVLP + ATL802, along with less neutrophil infiltration.

Conclusions: Severely injured donation after circulatory death lungs subjected to 2 hours of warm ischemia are transplanted successfully after enhanced EVLP with targeted drug therapy. Increased use of lungs after uncontrolled donor cardiac death and prolonged warm ischemia may be possible and may improve transplant wait list times and mortality. (J Thorac Cardiovasc Surg 2017;154:1811-20)

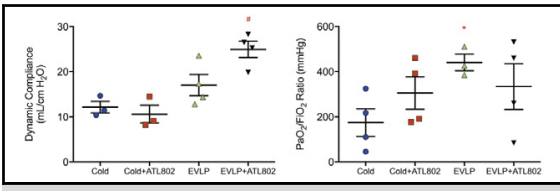

Lung compliance and oxygenation capacity after transplant with and without enhanced ex vivo lung perfusion

\section{Central Message}

Targeted drug therapy during ex vivo lung perfusion improves outcomes after transplantation of severely injured lungs.

\section{Perspective}

A significant dichotomy exists between the number of acceptable donor lungs and patients needing a transplant. Increasing use of donation after circulatory death lungs subjected to prolonged warm ischemia may decrease wait list times and mortality. Enhanced ex vivo lung perfusion with targeted drug therapy may improve outcomes.

See Editorial Commentary page 1821
Lung transplantation is a life-saving operation for patients with end-stage lung disease but is accompanied by significant hurdles that must be overcome to ensure a positive result. Central to the discussion is the shortage of acceptable donor lungs, given the conservative acceptance criteria used by most surgeons and the increased risk of primary graft dysfunction (PGD) with transplantation of marginal lungs. ${ }^{1}$ Considering that outcomes after lung
From the Departments of ${ }^{\text {a Surgery and }}{ }^{\mathrm{b}}$ Pathology, University of Virginia Health System, Charlottesville, Va.

Supported by National Institutes of Health T32HL007849 (to I.L.K.) and R01HL119218 (to I.L.K. and V.E.L.). The authors had full control of the design of the study, methods used, results, data analysis, and production of the written manuscript.

Read at the 96th Annual Meeting of The American Association for Thoracic Surgery, Baltimore, Maryland, May 14-18, 2016.
Received for publication May 14, 2016; revisions received Dec 5, 2016; accepted for publication Feb 10, 2017; available ahead of print May 5, 2017.

Address for reprints: Irving L. Kron, MD, University of Virginia Health System, PO Box 800679, Charlottesville, VA 22908 (E-mail: ilk@ virginia.edu). $0022-5223 / \$ 36.00$

Copyright (c) 2017 by The American Association for Thoracic Surgery http://dx.doi.org/10.1016/j.jtcvs.2017.02.072 


$$
\begin{aligned}
& \text { Abbreviations and Acronyms } \\
& \mathrm{A}_{2 \mathrm{~B}} \mathrm{R}=\text { adenosine } \mathrm{A}_{2 \mathrm{~B}} \text { receptor } \\
& \mathrm{BAL}=\text { bronchoalveolar lavage } \\
& \mathrm{DCD}=\text { donation after circulatory death } \\
& \mathrm{EVLP}=\text { ex vivo lung perfusion } \\
& \mathrm{FiO}_{2}=\text { fraction of inspired oxygen } \\
& \mathrm{HPF}=\text { high-powered field } \\
& \mathrm{IL}=\text { interleukin } \\
& \mathrm{IR}=\text { ischemia }- \text { reperfusion } \\
& \mathrm{LA}=\text { left atrial/atrium } \\
& \mathrm{PA}=\text { pulmonary artery } \\
& \mathrm{PaO} \mathrm{P}_{2}=\text { partial pressure of oxygen } \\
& \mathrm{PGD}=\text { primary graft dysfunction }
\end{aligned}
$$

Scanning this QR code will take
you to a supplemental video. To
view the AATS 2016 Webcast,
see the URL next to the webcast
thumbnail.

transplantation are the worst of any solid organ, strategies to optimize lung use and increase the likelihood of a successful outcome are needed. ${ }^{2}$

The expansion of donor acceptance criteria to include donation after circulatory death (DCD) lungs is one such approach that may substantially increase the pool of available organs. ${ }^{3}$ Currently, DCD lungs are used in less than $2 \%$ of lung transplants per year because of the increased risk of ischemia-reperfusion (IR) injury, a major cause of PGD and a risk factor for the development of chronic graft rejection., ${ }^{2,4}$ The use of ex vivo lung perfusion (EVLP) before transplantation may help alleviate the resultant IR injury. ${ }^{5}$ The use of EVLP to perform donor lung assessment followed by targeted therapeutic rehabilitation may allow for successful transplantation of otherwise-unacceptable lungs.

Targeting various cellular receptors in the lung, such as adenosine and sphingosine-1-phosphate receptors, our laboratory has shown improved outcomes and attenuation of IR injury after transplantation. ${ }^{6,7}$ Adenosine, a bioactive nucleoside, plays a significant role in purinergic signaling during inflammation through its interaction with $4 \mathrm{G}$ protein-coupled receptors $\left(\mathrm{A}_{1}, \mathrm{~A}_{2 \mathrm{~A}}, \mathrm{~A}_{2 \mathrm{~B}}, \mathrm{~A}_{3}\right) .{ }^{8}$ Altering the level of adenosine receptor signaling with targeted drug delivery during EVLP may help improve outcomes after lung transplantation. The role of adenosine $\mathrm{A}_{2 \mathrm{~B}}$ receptor $\left(\mathrm{A}_{2 \mathrm{~B}} \mathrm{R}\right)$ activation has been found to be both proinflammatory and anti-inflammatory in different experimental models of lung injury. ${ }^{9-12}$ Our laboratory demonstrated that it is proinflammatory and that selective antagonism of $\mathrm{A}_{2 \mathrm{~B}} \mathrm{R}$ attenuates IR injury. ${ }^{13}$
The objective of the current study was to determine whether lungs procured after donor cardiac death and prolonged warm ischemia could be rehabilitated with EVLP and successfully transplanted, using a porcine model of lung transplantation. We hypothesized that use of EVLP with addition of an $\mathrm{A}_{2 \mathrm{~B}} \mathrm{R}$ antagonist, as targeted drug therapy during the 4-hour ex vivo perfusion period, would allow for successful rehabilitation and transplantation of DCD lungs exposed to 2 hours of warm ischemia. The use of lungs for transplantation after uncontrolled donor cardiac death in the field could increase the pool of available organs, increase the number of lung transplants per year, and decrease wait list times and mortality.

\section{MATERIALS AND METHODS \\ Animals and Study Groups}

This study complied with the 1996 Guide for the Care and Use of Laboratory Animals as recommended by the US National Institutes of Health. The University of Virginia Animal Care and Use Committee approved the study protocol, and all animals received humane care.

Mature domestic swine of both sexes (19-42 kg) underwent hypoxic cardiac arrest, followed by 2 hours of warm ischemia before cold preservation flush and procurement of the lungs. Two hours of warm ischemia time reflects the estimated amount of time necessary to procure lungs after uncontrolled donor cardiac death in the field. Donor lungs were randomized to 4 groups ( $n=4$ /group): 4 hours of cold preservation at $4^{\circ} \mathrm{C}$ (Cold), 4 hours of cold preservation at $4^{\circ} \mathrm{C}$ with the addition of ATL802 during the reperfusion period (Cold + ATL802), 4 hours of normothermic EVLP with Steen Solution (XVIVO Perfusion Inc, Englewood, Colo) (EVLP), or 4 hours of EVLP supplemented with ATL802 (EVLP + ATL802) (Figure 1). In all groups, the left lung subsequently was transplanted into a size-matched recipient and reperfused for 4 hours in vivo. ATL802 (Lewis and Clark Pharmaceuticals, Charlottesville, Va), a selective $\mathrm{A}_{2 \mathrm{~B}} \mathrm{R}$ antagonist, was given to groups Cold + ATL802 (via external jugular vein at start of reperfusion period) and EVLP + ATL802 (added to Steen at start of ex vivo perfusion period) as targeted anti-inflammatory drug therapy at a bolus dose of $1 \mathrm{mg} / \mathrm{kg}$, based on previous studies. ${ }^{13,14}$ ATL802 currently is being used for preclinical studies only to determine the efficacy of $A_{2 B} R$ antagonism.

\section{Donor-Procurement Procedure}

Procurement of donor lungs was performed as previously described (Video 1). ${ }^{15}$ Ketamine $(50 \mathrm{mg} / \mathrm{kg}$ ) and xylazine $(5 \mathrm{mg} / \mathrm{kg})$ were used for induction of anesthesia and intubation. Isoflurane $(3 \%)$ and 1.0 fraction of inspired oxygen $\left(\mathrm{FiO}_{2}\right)$ were used to maintain anesthesia. Animals were ventilated (tidal volume $8 \mathrm{~mL} / \mathrm{kg}$, respiratory rate 16-20 breaths $/ \mathrm{min}$, positive end-expiratory pressure $5 \mathrm{cmH}_{2} \mathrm{O}$ ) and an initial arterial blood gas sample was analyzed. All donor animals received systemic heparin (200 U/kg; Hospira Inc, Lake Forest, Ill) and had continuous electrocardiogram monitoring in place before we clamped the endotracheal tube and induced hypoxic cardiac arrest. Donor animals underwent 2 hours of warm ischemia from the time asystole was confirmed on the cardiac monitor.

A median sternotomy was then performed and a cardioplegia cannula (Terumo Heart Inc, Ann Arbor, Mich) was inserted into the main pulmonary artery (PA) to deliver Prostaglandin-E1 (500 $\mu \mathrm{g}$; Pfizer Inc, New York, NY) and cold Perfadex (XVIVO Perfusion Inc). A total of 1.5 liters of Perfadex supplemented with 15,000 IU of heparin was flushed through the lungs after venting the left atrial (LA) appendage and ligating the vena cava. Ice slush was introduced into the thorax to rapidly cool the lungs. The trachea was clamped mid-inspiration and the heart-lung bloc was explanted. 


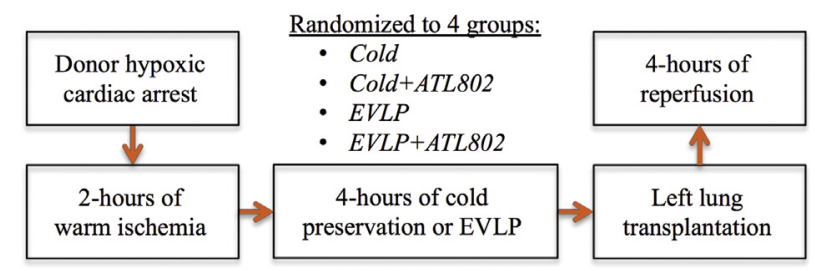

FIGURE 1. Schematic of experiment. Cold, Transplantation after 4 hours of cold preservation; Cold + ATL802, transplantation after 4 hours of cold preservation with administration of ATL802 during reperfusion; EVLP, transplantation after 4 hours of EVLP; EVLP + ATL802, transplantation after 4 hours of EVLP with administration of ATL802 during ex vivo perfusion.

For groups Cold and Cold + ATL802, the heart and right lung were removed on the back table and preparation of the left bronchus, PA, and LA cuff was completed. Retrograde flush with an additional $500 \mathrm{~mL}$ of cold Perfadex with heparin was completed and the lungs were placed in a protective plastic bag and stored at $4{ }^{\circ} \mathrm{C}$ for 4 hours. For groups EVLP and EVLP + ATL802, the heart was removed on the back table and the trachea, main PA, and LA cuff were prepared to allow for placement of the EVLP cannulas.

\section{EVLP}

Lungs randomized to groups EVLP and EVLP + ATL802 underwent 4 hours of normothermic EVLP. ${ }^{16,17}$ A yellow cannula (XVIVO Perfusion Inc) was placed in the main PA, a green cannula (XVIVO Perfusion Inc) was sutured to the LA cuff, and a 7-0 endotracheal tube was placed into the trachea. An additional $500 \mathrm{~mL}$ of cold Perfadex was flushed retrograde.

EVLP was initiated on both lungs as previously described (Video 1). ${ }^{18}$ The circuit was primed with $2 \mathrm{~L}$ of Steen supplemented with cefazolin $(500 \mathrm{mg}$; APP Pharmaceuticals, Schaumburg, Ill), methylprednisolone (500 mg; Pfizer Inc), and heparin (10,000 IU). ATL802 was added to the ex vivo perfusate for lungs randomized to EVLP + ATL802 and dimethyl sulfoxide (vehicle) was added for group EVLP. Surgeons were blinded as to whether the perfusate was supplemented with the treatment drug or vehicle. Flow was initiated $(0.2 \mathrm{~L} /$ $\mathrm{min}$ ) and LA pressures maintained between 0 and $5 \mathrm{~mm} \mathrm{Hg}$. The perfusate was warmed to $37^{\circ} \mathrm{C}$ over 30 minutes. Flow was titrated up to $40 \%$ of estimated cardiac output (100 mL/kg donor body weight) and when the perfusate

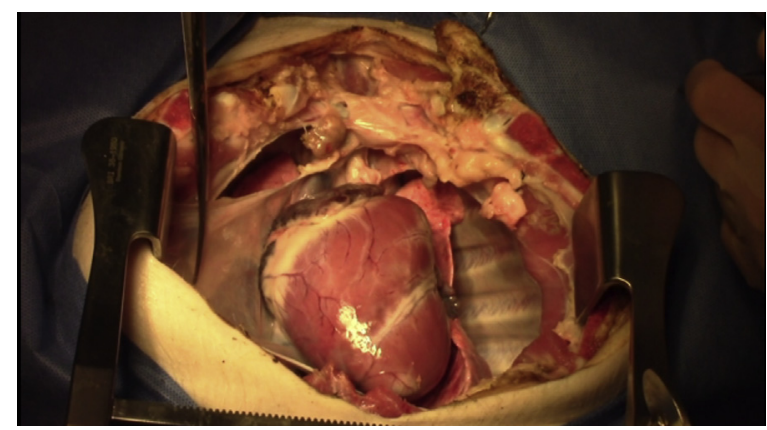

VIDEO 1. University of Virginia Porcine Lung Procurement and Transplant Procedure: Deceased donor harvest (00:09), ex vivo lung perfusion cannulation (03:30), left lung back table preparation (06:20), recipient pneumonectomy (08:09), left lung transplant (11:50), and left pulmonary vein sampling (12:59). Video available at: http://www. jtcvsonline.org/article/S0022-5223(17)30678-5/addons. reached $32^{\circ} \mathrm{C}$, ventilation was started (tidal volume $8 \mathrm{~mL} / \mathrm{kg}$, respiratory rate 8 breaths/min, positive end-expiratory pressure $5.0 \mathrm{cmH}_{2} \mathrm{O}, \mathrm{FiO}_{2} \mathrm{0.21}$ ). A trigas mixture ( $86 \%$ nitrogen, $8 \%$ carbon dioxide, $6 \%$ oxygen) was used to deoxygenate the perfusate.

Samples from the PA inflow and LA outflow were collected hourly after a 15-minute challenge with $1.0 \mathrm{FiO}_{2}$ to measure the partial pressure of oxygen $\left(\mathrm{PaO}_{2}\right)$. Airway pressures were measured hourly and used to calculate dynamic compliance. After 4 hours of EVLP, lungs were flushed anterograde with cold Perfadex $(500 \mathrm{~mL})$ and the left lung was separated off and prepared for transplantation.

\section{Lung Transplant Procedure}

Recipient animals were anesthetized and ventilated similar to donors. A multiaccess catheter with PA catheter and an arterial catheter were placed. The animal was administered lidocaine $(50 \mathrm{mg})$ and heparin (5000 IU). The transplant procedure was performed as previously described: left lateral thoracotomy, left pneumonectomy, left lung transplant (running sutures for anastomoses: end-to-end bronchial, end-to-end PA, and LA cuff to recipient LA appendage) (Video 1$){ }^{7}$ At the start of reperfusion, ATL802 was administered via external jugular vein injection for lungs randomized to group Cold + ATL802.

\section{Posttransplant Reperfusion}

In vivo reperfusion was maintained for 4 hours. Airway pressure measurements and systemic arterial blood gases were performed every 30 minutes. Low-pressure lung recruitment was performed before each set of measurements. Superior and inferior pulmonary vein blood samples were obtained after 2 hours and at the completion of 4 hours of reperfusion for direct left lung $\mathrm{PaO}_{2}$ measurements. Adequate hemodynamics and acid/base status were maintained with use of normal saline, epinephrine, and sodium bicarbonate to meet the following goals: $\mathrm{pH} 7.35$ to 7.45 , base excess $>-5$, and mean arterial pressure $>55 \mathrm{~mm} \mathrm{Hg}$. The lung was explanted after 4 hours of reperfusion and the animal euthanized.

\section{Pulmonary Edema}

Left lungs were weighed just before transplant and immediately after explant. Percent gross weight change from pretransplantation to postreperfusion was calculated to determine amount of pulmonary edema.

\section{Cytokine Measurements}

After explantation, 2 fresh tissue samples were obtained (upper and lower portion of lower lobe), flash frozen in liquid nitrogen, and stored at $-80^{\circ} \mathrm{C}$. FastPrep-24 (MP Biomedicals, Santa Ana, Calif) was used to homogenize tissue. Bicinchoninic acid protein assay (Pierce, Rockford, Ill) was used to determine total protein concentration in the supernatant of each homogenized tissue sample. Bronchoalveolar lavage (BAL) of the upper lobe was performed with $30 \mathrm{~mL}$ of normal saline, centrifuged, and stored at $-80^{\circ} \mathrm{C}$. A commercially available multiplex immunosorbent assay (EMD Millipore, Billerica, Mass) was used to measure levels of interleukin (IL)- $1 \alpha, 1 \beta, 4,6,8$, $10,12,18$, and tumor necrosis factor- $\alpha$ in tissue supernatant (normalized to equal protein concentrations) and BAL.

\section{Histopathologic Assessment}

The lower lobe was instilled with $10 \%$ buffered formalin via the bronchus after all fresh tissue sampling was complete and then submerged in formalin. After storage overnight, peripheral lung tissue samples ( $n=4 /$ lung) were obtained, paraffin-embedded, and sectioned. One histology slide from each sample was stained with hematoxylin-eosin and 2 histology slides were used for immunohistochemistry evaluation of neutrophil infiltration.

The hematoxylin-eosin-stained slides were assessed by a masked pathologist for presence of lung injury. Each slide was scored based on the following 3 components: polymorphonuclear cells per $40 \times$ high-powered field (HPF) $(0=<5,1=6-10,2=11-20,3=>20)$, alveolar 
edema $(0=<5 \%, 1=6 \%-25 \%, 2=26 \%-50 \%, 3=>50 \%)$, and interstitial inflammation $(0=$ none, $1=$ minimal, $2=$ moderate, $3=$ severe), as previously described. ${ }^{7}$

For neutrophil immunohistochemistry staining, the primary antibody used was mouse monoclonal antiporcine neutrophil antibody (MBA Biomedicals, Augst, Switzerland) and secondary antibody used was donkey anti-mouse IgG (Jackson ImmunoResearch Laboratories Inc, West Grove, Pa). After the addition of avidin-biotin complex, slides were incubated for 30 minutes at room temperature, followed by incubation with 3,3-diaminobenzidine tetrahydrochloride (Dako Inc, Carpinteria, Calif) to produce a brown precipitate, and finally counterstained with hematoxylin. ${ }^{12}$ Five microscopic photographs of each slide were taken at $40 \times$ magnification. The number of neutrophils per HPF was counted by a masked reviewer and averaged per tissue sample to account for potential injury heterogeneity.

\section{Statistical Analysis}

One-way analysis of variance with the Bonferroni multiple comparisons test and Student $t$ test were used to determine statistical significance between groups. Prism 6 (GraphPad Software Inc, La Jolla, Calif) was used to perform statistical calculations and all data were reported as mean \pm standard error of the mean, with $P$ value for significance of .05 .

\section{RESULTS}

\section{Lung Function}

After transplantation and 4 hours of in vivo reperfusion, dynamic compliance was significantly greater in group EVLP + ATL802 compared with the vehicle EVLP group $\left(25.0 \pm 1.8\right.$ vs $\left.17.0 \pm 2.4 \mathrm{~mL} / \mathrm{cmH}_{2} \mathrm{O}, P=.04\right)$, and compared with both non-EVLP groups (Cold: $12.2 \pm 1.3$, $P=.004$ and Cold + ATL802: $10.6 \pm 2.0 \mathrm{~mL} / \mathrm{cmH}_{2} \mathrm{O}$, $P=.002$ ) (Figure 2, A). Oxygenation capacity of the transplanted lung after 4 hours of reperfusion was greatest in the EVLP group $(440.4 \pm 37.0 \mathrm{~mm} \mathrm{Hg})$ and significant compared with Cold $(174.0 \pm 61.3 \mathrm{~mm} \mathrm{Hg}, P=.037)$ (Figure 2, $B$ ). There were no significant differences in final $\mathrm{PaO}_{2} / \mathrm{FiO}_{2}$ ratios between groups Cold, Cold + ATL802, and EVLP + ATL802.

Before inducing hypoxic cardiac arrest, donor animals from all groups had similar $\mathrm{PaO}_{2} / \mathrm{FiO}_{2}$ ratios (Cold: $501.7 \pm 28.9$,
Cold + ATL802: $510.2 \pm$ 29.9, EVLP: $454.8 \pm 17.0$, EVLP + ATL802: $490.3 \pm 39.8 \mathrm{mmHg}, P=.59$ ) with an overall mean donor $\mathrm{PaO}_{2} / \mathrm{FiO}_{2}$ ratio of $489.3 \pm 14.5 \mathrm{~mm}$ $\mathrm{Hg}$. After the endotracheal tube was clamped, the mean time to death for all donor animals was $22.6 \pm 2.0$ minutes, with no difference between groups $(P=.2)$.

During the 4-hour EVLP period, no significant differences in oxygenation capacity or dynamic compliance were observed between the EVLP and EVLP + ATL802 groups, although the hourly mean values for both parameters were consistently greater in EVLP + ATL802 (Figure 3). By hour 1 of EVLP, the mean $\mathrm{PaO}_{2} / \mathrm{FiO}_{2}$ ratios for both groups were greater than $300 \mathrm{~mm} \mathrm{Hg}$ (EVLP: $375 \pm 23.3$, EVLP + ATL802: $427.2 \pm 83.6 \mathrm{~mm} \mathrm{Hg}$ ) and remained elevated at the completion of 4 hours of EVLP (EVLP: $376.7 \pm 61.0$, EVLP + ATL802: $384.2 \pm 102.0 \mathrm{~mm} \mathrm{Hg}$ ).

The mean $\mathrm{PaO}_{2} / \mathrm{FiO}_{2}$ ratios from the start of the experiment to conclusion of the 4-hour reperfusion period for the 2 untreated groups (Cold and EVLP) are shown in Figure 4. The Cold group decreased significantly from an initial donor $\mathrm{PaO}_{2} / \mathrm{FiO}_{2}$ ratio of $501.7 \pm 28.9 \mathrm{~mm} \mathrm{Hg}$ to a postreperfusion mean of $174.0 \pm 61.3 \mathrm{~mm} \mathrm{Hg}(P=.003)$, whereas the final postreperfusion $\mathrm{PaO}_{2} / \mathrm{FiO}_{2}$ ratio for the EVLP group was not significantly different compared with the donor prehypoxia ratio $(440.4 \pm 37.0$ vs $454.8 \pm 17.0, P=.71)$.

\section{Hemodynamic Support}

During the reperfusion period, intravenous normal saline, epinephrine, and sodium bicarbonate were used judiciously to maintain adequate hemodynamics and appropriate acid/base status. Recipient animals in EVLP + ATL802 were the most stable, requiring the least amount of fluids $(0.7 \pm 0.1 \mathrm{~L})$, epinephrine $(1.2 \pm 0.4 \mathrm{mg})$, and sodium bicarbonate (1.0 $\pm 0.0 \mathrm{amps})$ during the reperfusion period (Table 1).

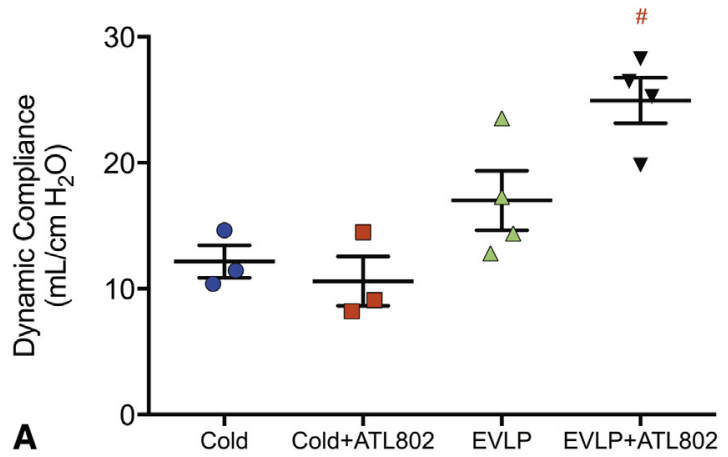

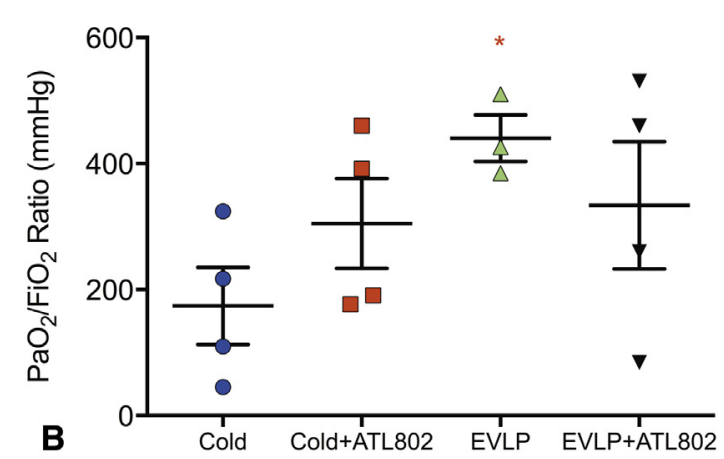

FIGURE 2. A, Final dynamic compliance and (B) oxygenation $\left(\mathrm{PaO}_{2} / \mathrm{FiO}\right)$ at the completion of 4 hours of reperfusion. Cold, Transplantation after 4 hours of cold preservation; Cold + ATL802, transplantation after 4 hours of cold preservation with administration of ATL802 during reperfusion; EVLP, transplantation after 4 hours of EVLP; EVLP + ATL802, transplantation after 4 hours of EVLP with administration of ATL802 during ex vivo perfusion; $\mathrm{PaO}_{2} / \mathrm{FiO}_{2}$, partial pressure of oxygen/fraction of inspired oxygen. $\# P=.04$ versus EVLP, $P=.002$ versus Cold + ATL802, and $P=.004$ versus Cold, $* P=.037$ versus Cold. 

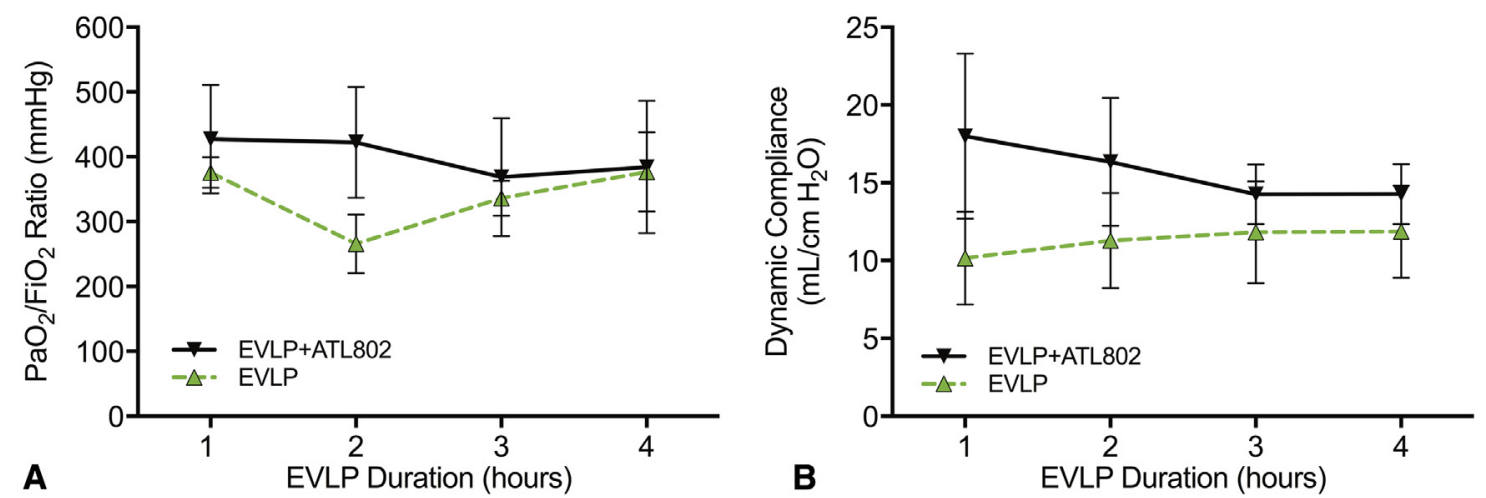

FIGURE 3. A, Oxygenation $\left(\mathrm{PaO}_{2} / \mathrm{FiO}_{2}\right)$ and (B) dynamic compliance recorded hourly during EVLP. $\mathrm{PaO}_{2} / \mathrm{FiO}_{2}$, Partial pressure of oxygen/fraction of inspired oxygen; EVLP, transplantation after 4 hours of EVLP; EVLP + ATL802, transplantation after 4 hours of EVLP with administration of ATL802 during ex vivo perfusion.

\section{Pulmonary Edema}

Compared with Cold, lungs that underwent 4 hours of EVLP without ATL802 had significantly less weight gain from pretransplantation to postreperfusion (Cold: 120\% $\pm 23 \%$ vs EVLP: $20 \% \pm 20 \%, P=.037)$ and trended towards significance for lungs in EVLP + ATL802 (28\% $\pm 10 \%, P=.056$ ) (Figure 5, A). No significant differences were observed between Cold and Cold + ATL802 (116\% $\pm 41 \%)$ or between EVLP and EVLP + ATL802.

\section{Cytokine Expression}

Proinflammatory cytokines were assessed in homogenized tissue supernatant and BAL fluid after the reperfusion period. A significant decrease was identified in levels of IL-12 when we compared EVLP with EVLP + ATL802 (tissue: $132.5 \pm 37.7$ vs $36.3 \pm 17.5$ $\mathrm{pg} / \mathrm{mL}, P=.007$; BAL: $360.0 \pm 106.7$ vs $85.0 \pm 34.0$ $\mathrm{pg} / \mathrm{mL}, P=.046$ ) (Figure $5, B$ ). No other significant differences were identified.

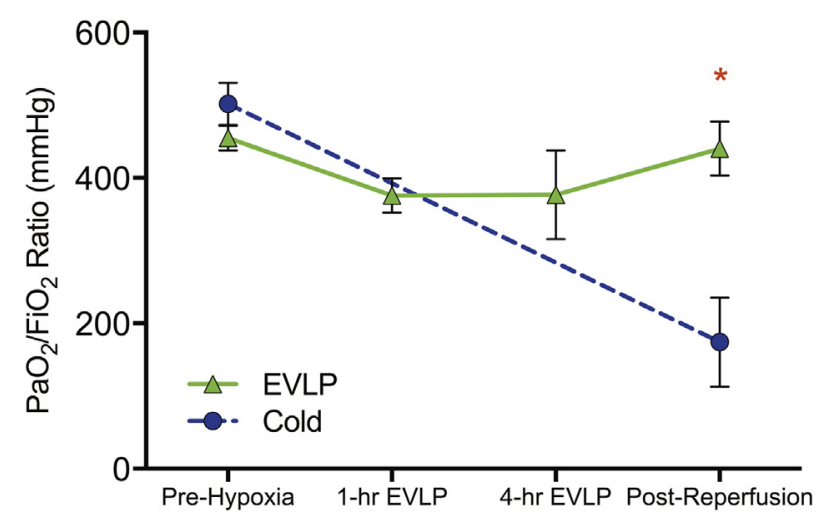

FIGURE 4. Oxygenation capacity $\left(\mathrm{PaO}_{2} / \mathrm{FiO}_{2}\right)$ of groups without drug treatment recorded at 4 time points: donor animal before hypoxia (Pre-hypoxia), 1 hour into EVLP (1-hr EVLP), at the completion of EVLP (4-hr EVLP), and recipient after 4 hours of reperfusion (Post-Reperfusion). $\mathrm{PaO}_{2} / \mathrm{FiO}_{2}$, Partial pressure of oxygen/fraction of inspired oxygen; EVLP, transplantation after 4 hours of EVLP; Cold, transplantation after 4 hours of cold preservation. $* P=.037$.

\section{Lung Injury Severity Score}

Although EVLP + ATL802 had the lowest mean composite lung injury severity score (composed of neutrophil infiltration, alveolar edema, and interstitial inflammation), there were no significant differences observed between groups (Cold: $4.31 \pm 0.70$, Cold + ATL802: $3.81 \pm 0.89$, EVLP: $5.94 \pm 0.90$, EVLP + ATL802: $2.94 \pm 1.35, P=.24)$.

\section{Neutrophil Infiltration}

Immunohistochemistry stained slides were compared between all 4 groups by the use of samples from 2 distinct lung regions, with 5 HPF counts per sample. Significantly less neutrophils were seen in group EVLP + ATL802 compared with Cold $(56.0 \pm 6.7$ vs $122.8 \pm 16.2$, $P=.002)$ and compared with EVLP $(56.0 \pm 6.7$ vs $111.7 \pm 10.0, P=.012$ ) (Figure 6).

\section{DISCUSSION}

Using a porcine model of left lung transplantation, in the present study we sought to determine the ability of EVLP, with and without the addition of targeted drug therapy, to rehabilitate DCD lungs exposed to 2 hours of warm ischemia. Dynamic compliance 4 hours after reperfusion

TABLE 1. Intravenous fluid, epinephrine, and sodium bicarbonate requirements during 4-hour reperfusion period

\begin{tabular}{lccc}
\hline & $\begin{array}{c}\text { Intravenous } \\
\text { fluid, L }\end{array}$ & $\begin{array}{c}\text { Epinephrine, } \\
\text { mg }\end{array}$ & $\begin{array}{c}\text { Sodium } \\
\text { bicarbonate, amps }\end{array}$ \\
\hline Cold & $1.2 \pm 0.3$ & $7.9 \pm 4.2$ & $1.0 \pm 0.4$ \\
Cold + ATL802 & $2.2 \pm 0.6$ & $14.1 \pm 6.3$ & $3.5 \pm 1.0$ \\
EVLP & $1.0 \pm 0.3$ & $2.1 \pm 0.3$ & $0.8 \pm 0.5$ \\
EVLP + ATL802 & $0.7 \pm 0.1$ & $1.2 \pm 0.4$ & $1.0 \pm 0.0$ \\
\hline
\end{tabular}

Values are mean \pm SE. Cold, Transplantation after 4-hours of cold preservation Cold $+A T L 802$, transplantation after 4 hours of cold preservation with administration of ATL802 during reperfusion; EVLP, transplantation after 4 hours of EVLP; EVLP +ATL802, transplantation after 4 hours of EVLP with administration of ATL802 during ex vivo perfusion. 

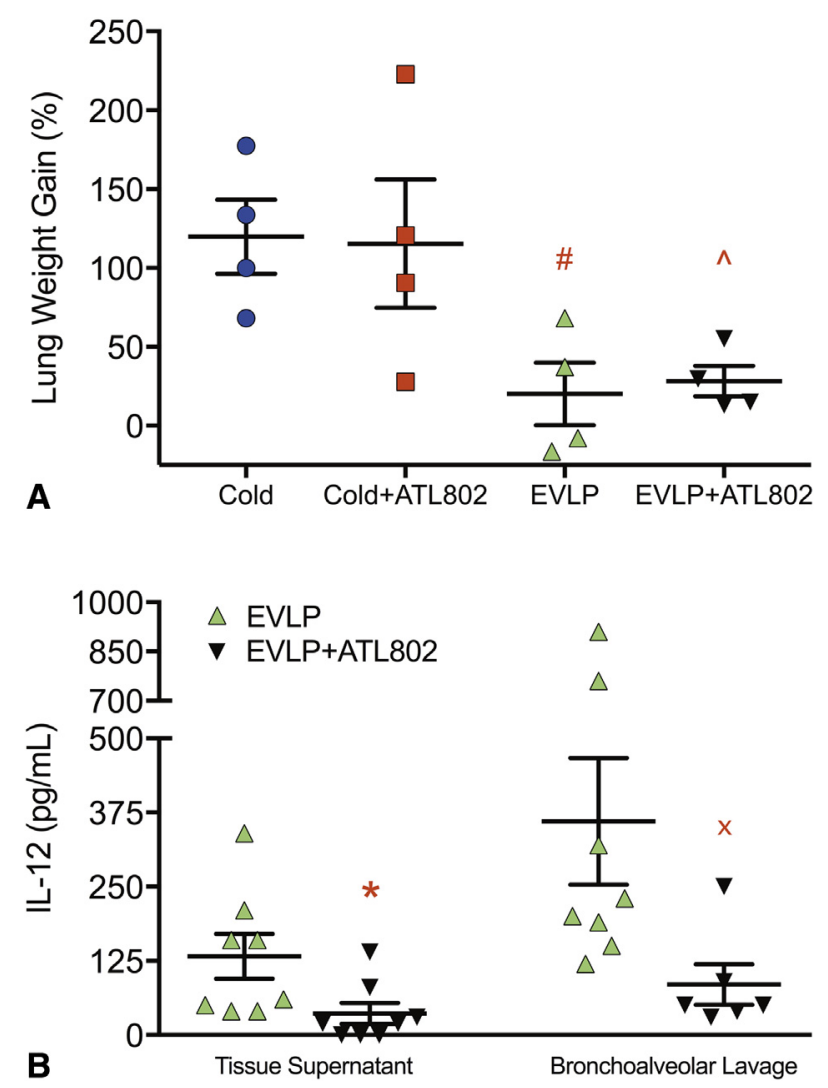

FIGURE 5. A, Percentage increase in gross lung weight from pretransplant to postreperfusion and (B) tissue supernatant and bronchoalveolar lavage IL-12 levels after reperfusion. Cold, Transplantation after 4 hours of cold preservation; Cold + ATL802, transplantation after 4 hours of cold preservation with administration of ATL802 during reperfusion; EVLP, transplantation after 4 hours of EVLP; $E V L P+A T L 802$, transplantation after 4 hours of EVLP with administration of ATL802 during ex vivo perfusion; $I L$, interleukin. $\# P=.037$ versus Cold, $\stackrel{P}{P}=.056$ versus Cold, ${ }^{*} P=.007, \mathrm{x} P=.046$.

was improved in lungs treated with 4 hours of EVLP supplemented with an $\mathrm{A}_{2 \mathrm{~B}} \mathrm{R}$ antagonist (ATL802), and oxygenation was improved in lungs treated with EVLP alone compared with cold preservation. After the reperfusion period, lungs that received 4 hours of EVLP, with or without ATL802, demonstrated less percent weight gain compared with lungs that underwent 4 hours of cold preservation before transplant. The combination of EVLP plus ATL802 significantly reduced neutrophil infiltration after 4 hours of reperfusion, and a decrease in the amount of IL-12 expression was observed with the addition of ATL802 compared with EVLP alone. Collectively, DCD lungs exposed to 2 hours of warm ischemia can be transplanted successfully after 4 hours of EVLP as opposed to cold preservation, and targeted drug therapy during the ex vivo perfusion period may further improve outcomes.

Increasing the amount of warm ischemia time acceptable for donor lung procurement would allow for inclusion of uncontrolled DCD lungs from patients who experience cardiac arrest outside of a medical facility, with heparin administration as the only intervention possibly needed before procurement. Further investigation may show that heparin administration is not necessary if lungs are flushed with a fibrinolytic agent before EVLP. This strategy for increasing the pool of available donor lungs may shorten wait-list times and improve mortality for deteriorating patients with end-stage pulmonary disease and is gaining support clinically as the supply-demand chasm continues to widen. ${ }^{19} \mathrm{~A}$ case report of successful transplantation after EVLP of human DCD lungs exposed to 4 hours of warm ischemia has been reported. ${ }^{20}$ Unfortunately, longer ischemic times increase the risk of IR injury and PGD, but EVLP has been shown to be protective and beneficial when transplanting marginal donor lungs. ${ }^{21}$ Our results support the use of EVLP compared with cold preservation alone, as the majority of the benefit seen in this study can be attributed to EVLP and not the treatment drug.

The present study employed the use of ATL802, an $\mathrm{A}_{2 \mathrm{~B}} \mathrm{R}$ antagonist, as targeted drug therapy to reduce inflammation and IR injury after transplantation. Both activation and inhibition of $\mathrm{A}_{2 \mathrm{~B}} \mathrm{Rs}$ have been shown to decrease lung inflammation. ${ }^{9-12}$ Previous work from our laboratory implicated resident pulmonary cells as opposed to bone marrow-derived cells as the location of $\mathrm{A}_{2 \mathrm{~B}} \mathrm{R}$ signaling, with a resultant decrease in cytokine expression and neutrophil activation. ${ }^{9}$ In a mouse model of acute lung injury, Hoegl and colleagues ${ }^{22}$ identified alveolar epithelial cells as the location of $A_{2 B} R$ signaling, which supports the findings from our laboratory showing attenuation of mouse lung IR with $\mathrm{A}_{2 \mathrm{~B}} \mathrm{R}$ antagonism. ${ }^{13}$ The present study translated these findings into a large animal transplant model for the first time.

IL-12 is a proinflammatory cytokine secreted by tissue-resident macrophages and dendritic cells, which leads to increased production of interferon- $\gamma$ by T-helper cells. $^{23}$ IL-12, in conjunction with IL-18, an important component of inflammasome activation, has been implicated in the up-regulation of matrix degrading enzymes and T-cell infiltration in lung injury. ${ }^{24}$ In addition, adenosine signaling has been shown to inhibit IL-12 production, which may further support the use of adenosine receptor-targeted therapies to prevent inflammation. ${ }^{25}$ Two IL-12 antagonists, ustekinumab and briakinumab, currently are being tested in clinical trials as targeted drug therapy for immune-mediated inflammatory disease, including graft-vs-host disease. ${ }^{23}$ Targeted treatment to downregulate IL-12 expression may be a possible adjunctive therapy, delivered during the EVLP period, to attenuate IR injury and improve outcomes after lung transplantation.

Neutrophil activation and infiltration is dependent on various signaling pathways related to both innate and adaptive immunity. We have shown previously that $A_{2 A} R$ 


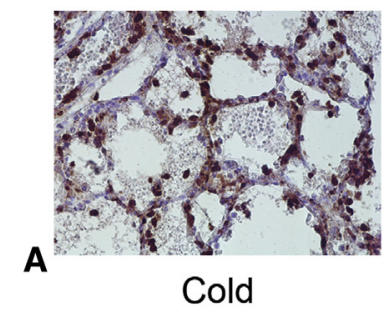

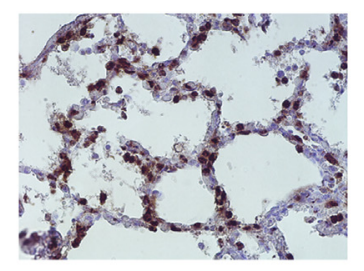

Cold+ATL802

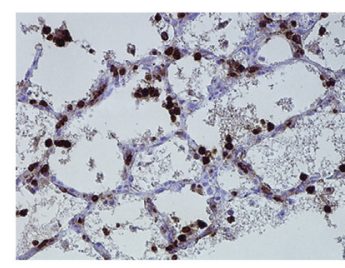

EVLP

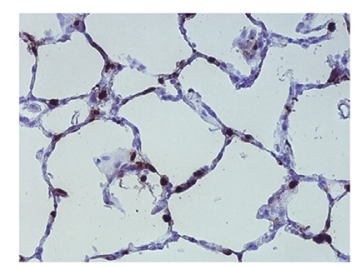

EVLP+ATL802

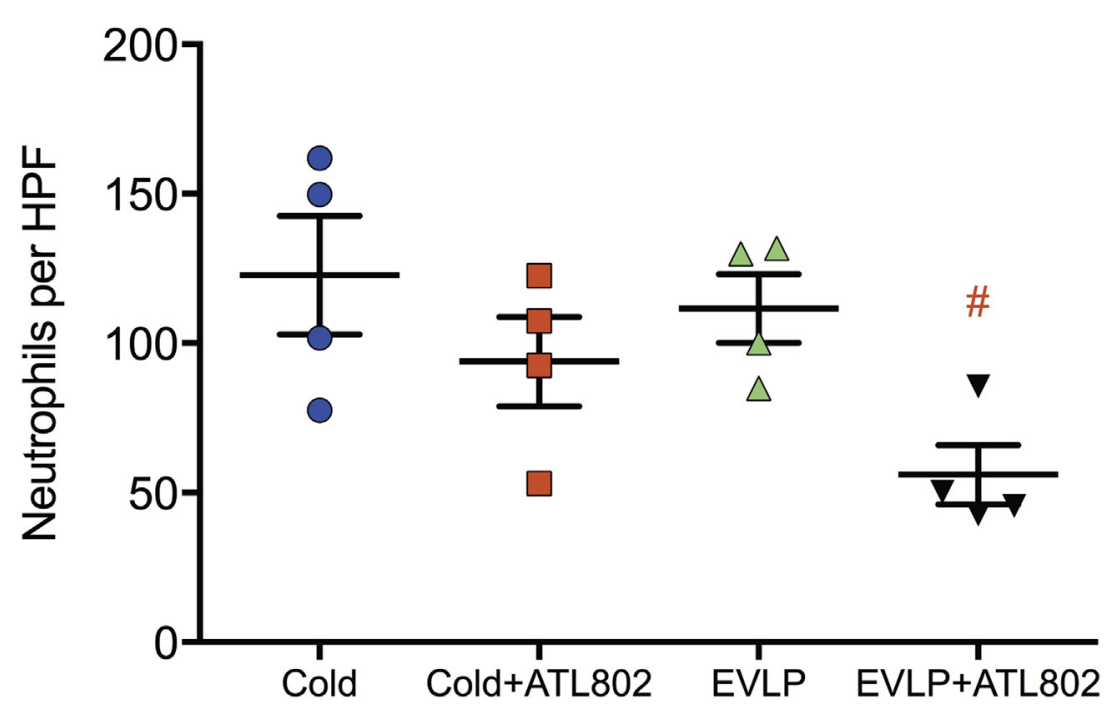

FIGURE 6. Immunohistochemistry staining for neutrophils. A, Representative sections (40× magnification). B, Neutrophils per HPF. Cold, Transplantation after 4 hours of cold preservation; Cold + ATL802, transplantation after 4 hours of cold preservation with administration of ATL802 during reperfusion; $E V L P$, transplantation after 4 hours of EVLP; EVLP + ATL802, transplantation after 4 hours of EVLP with administration of ATL802 during ex vivo perfusion; $H P F$, high-powered field. $\# P=.002$ versus Cold and $P=.012$ versus EVLP.

activation significantly attenuates neutrophil infiltration in a mouse model of lung IR injury, as well as after transplantation in a porcine model. ${ }^{15,26}$ In addition, neutrophil activation has been shown to worsen acute lung injury through the involvement of $\mathrm{A}_{3} \mathrm{Rs}^{27}$ The present study shows evidence for a decrease in neutrophil infiltration with ATL802 treatment during EVLP. No significant difference was observed between groups Cold and Cold + ATL802 when ATL802 was administered during reperfusion, as opposed to 4 hours before reperfusion (EVLP + ATL802). This timing difference may impact the drug's ability to alter signaling pathways in alveolar epithelial cells and future studies are needed to better understand this effect. The resuscitative requirements of Cold + ATL802 may be due to hemodynamic effects of systemic drug administration.

The findings are limited by low sample size, donor heparin administration, inherent variability with large animals, and the dichotomy between compliance and oxygenation values in EVLP + ATL802. Improved oxygenation was not observed with ATL802, which may be the result of low sample size, considering one animal had significantly low oxygenation $\left(\mathrm{PaO}_{2} / \mathrm{FiO}_{2}\right.$ of 84.35$)$. In addition, posttransplant compliance values represent both lungs. Studies further evaluating the role of $\mathrm{A}_{2 \mathrm{~B}} \mathrm{Rs}$ in acute lung injury are needed before making conclusions about the benefit of $\mathrm{A}_{2 \mathrm{~B}} \mathrm{R}$ antagonism as a treatment modality.

The use of EVLP as an assessment and rehabilitation platform to improve organ use may lead to a reduction in the critical shortage of donor lungs that meet acceptance criteria. Current functional measurements (oxygenation and compliance) used to assess lung quality may not be sufficient to fully predict success after transplantation, but measuring biomarkers, such as endothelin-1 or proinflammatory cytokines, during EVLP may improve our ability to correctly predict outcomes. ${ }^{28,29}$ In addition, EVLP provides an opportunity to provide targeted rehabilitative strategies based on the needs of each individual set of donor lungs. The administration of inhaled $\beta 2$-agonist and neutrophil elastase during EVLP has been shown to improve outcomes after transplantation. ${ }^{30,31}$ Potentially more beneficial is the opportunity to provide drug treatments, such as antibiotics, at concentration levels that would otherwise be detrimental if systemically administered to the recipient. ${ }^{32}$

In summary, the use of EVLP to rehabilitate uncontrolled DCD lungs subjected to prolonged warm ischemia is 
promising. Our findings of improved outcomes after transplantation with the use of EVLP and targeted drug therapy during the ex vivo perfusion period suggest that it may be possible to successfully transplant lungs procured from patients suffering cardiac death in the field. Expanding current acceptance criteria for donor lung procurement is needed to decrease wait list times and improve wait list mortality for patients with end-stage pulmonary disease. The use of EVLP to assess lung quality and administer targeted drug therapies prior to recipient allocation will allow for maximal organ use and may improve outcomes after transplantation.

\section{Webcast}

You can watch a Webcast of this AATS meeting presentation by going to: http://webcast.aats.org/2016/Video/ Monday/05-16-16_Room_340_1712_Charles-800.mp4.

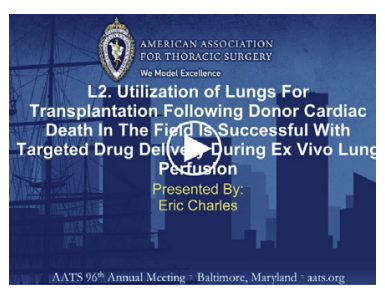

\section{Conflict of Interest Statement}

Authors have nothing to disclose with regard to commercial support.

The authors extended special appreciation to Tony Herring, Cindy Dodson, Sheila Hammond, and the UVA Histology Core for their support of this project.

\section{References}

1. Chaney J, Suzuki Y, Cantu E III, van Berkel V. Lung donor selection criteria. J Thorac Dis. 2014;6:1032-8.

2. Valapour M, Skeans MA, Heubner BM, Smith JM, Hertz MI, Edwards LB, et al. OPTN/SRTR 2013 Annual Data Report: lung. Am J Transplant. 2015;15(suppl 2):1-28.

3. Algahim MF, Love RB. Donation after circulatory death: the current state and technical approaches to organ procurement. Curr Opin Organ Transplant. 2015;20:127-32.

4. Fiser SM, Tribble CG, Long SM, Kaza AK, Kern JA, Jones DR, et al. Ischemiareperfusion injury after lung transplantation increases risk of late bronchiolitis obliterans syndrome. Ann Thorac Surg. 2002;73:1041-7; discussion 47-8.

5. Cypel M, Keshavjee S. Extending the donor pool: rehabilitation of poor organs. Thorac Surg Clin. 2015;25:27-33.

6. Stone ML, Sharma AK, Zhao Y, Charles EJ, Huerter ME, Johnston WF, et al. Sphingosine-1-phosphate receptor 1 agonism attenuates lung ischemiareperfusion injury. Am J Physiol Lung Cell Mol Physiol. 2015;308:L1245-52.

7. Wagner CE, Pope NH, Charles EJ, Huerter ME, Sharma AK, Salmon MD, et al Ex vivo lung perfusion with adenosine A2A receptor agonist allows prolonged cold preservation of lungs donated after cardiac death. J Thorac Cardiovasc Surg. 2016;151:538-46.

8. Eltzschig HK, Sitkovsky MV, Robson SC. Purinergic signaling during inflammation. N Engl J Med. 2012;367:2322-33.
9. Anvari F, Sharma AK, Fernandez LG, Hranjec T, Ravid K, Kron IL, et al. Tissue-derived proinflammatory effect of adenosine A2B receptor in lung ischemia-reperfusion injury. J Thorac Cardiovasc Surg. 2010;140:871-7.

10. Pejman L, Omrani H, Mirzamohammadi Z, Shahbazfar AA, Khalili M, Keyhanmanesh R. The effect of adenosine A2A and A2B antagonists on tracheal responsiveness, serum levels of cytokines and lung inflammation in guinea pig model of asthma. Adv Pharm Bull. 2014;4:131-8.

11. Zhou Y, Schneider DJ, Morschl E, Song L, Pedroza M, Karmouty-Quintana H, et al. Distinct roles for the A2B adenosine receptor in acute and chronic stages of bleomycin-induced lung injury. J Immunol. 2011;186:1097-106.

12. Zhao Y, LaPar DJ, Steidle J, Emaminia A, Kron IL, Ailawadi G, et al. Adenosine signaling via the adenosine $2 \mathrm{~B}$ receptor is involved in bronchiolitis obliterans development. J Heart Lung Transplant. 2010;29:1405-14.

13. Huerter ME, Sharma AK, Zhao Y, Charles EJ, Kron IL, Laubach VE. Attenuation of pulmonary ischemia-reperfusion injury by adenosine A2B receptor antagonism. Ann Thorac Surg. 2016;102:385-93.

14. Cagnina RE, Ramos SI, Marshall MA, Wang G, Frazier CR, Linden J. Adenosine A2B receptors are highly expressed on murine type II alveolar epithelial cells. Am J Physiol Lung Cell Mol Physiol. 2009;297:L467-74.

15. LaPar DJ, Laubach VE, Emaminia A, Crosby IK, Hajzus VA, Sharma AK, et al. Pretreatment strategy with adenosine A2A receptor agonist attenuates reperfusion injury in a preclinical porcine lung transplantation model. J Thorac Cardiovasc Surg. 2011;142:887-94.

16. Cypel M, Yeung JC, Hirayama S, Rubacha M, Fischer S, Anraku M, et al. Technique for prolonged normothermic ex vivo lung perfusion. J Heart Lung Transplant. 2008;27:1319-25.

17. Emaminia A, Lapar DJ, Zhao Y, Steidle JF, Harris DA, Laubach VE, et al. Adenosine A(2)A agonist improves lung function during ex vivo lung perfusion. Ann Thorac Surg. 2011;92:1840-6.

18. Mulloy DP, Stone ML, Crosby IK, Lapar DJ, Sharma AK, Webb DV, et al. Ex vivo rehabilitation of non-heart-beating donor lungs in preclinical porcine model: delayed perfusion results in superior lung function. J Thorac Cardiovasc Surg. 2012;144:1208-15.

19. Mason DP, Brown CR, Murthy SC, Vakil N, Lyon C, Budev MM, et al. Growing single-center experience with lung transplantation using donation after cardiac death. Ann Thorac Surg. 2012;94:406-11; discussion 11-2.

20. Valenza F, Citerio G, Palleschi A, Vargiolu A, Fakhr BS, Confalonieri A, et al. Successful transplantation of lungs from an uncontrolled donor after circulatory death preserved in situ by alveolar recruitment maneuvers and assessed by ex vivo lung perfusion. Am J Transplant. 2016;16:1312-8.

21. Boffini M, Ricci D, Bonato R, Fanelli V, Attisani M, Ribezzo M, et al. Incidence and severity of primary graft dysfunction after lung transplantation using rejected grafts reconditioned with ex vivo lung perfusion. Eur J Cardiothorac Surg. 2014; 46:789-93.

22. Hoegl S, Brodsky KS, Blackburn MR, Karmouty-Quintana H, Zwissler B, Eltzschig HK. Alveolar epithelial A2B adenosine receptors in pulmonary protection during acute lung injury. J Immunol. 2015;195:1815-24.

23. Teng MW, Bowman EP, McElwee JJ, Smyth MJ, Casanova JL, Cooper AM, et al. IL-12 and IL-23 cytokines: from discovery to targeted therapies for immune-mediated inflammatory diseases. Nat Med. 2015;21:719-29.

24. Cero FT, Hillestad V, Loberg EM, Christensen G, Larsen KO, Skjonsberg OH. IL-18 and IL-12 synergy induces matrix degrading enzymes in the lung. Exp Lung Res. 2012;38:406-19.

25. Hasko G, Kuhel DG, Chen JF, Schwarzschild MA, Deitch EA, Mabley JG, et al. Adenosine inhibits $\mathrm{IL}-12$ and TNF-[alpha] production via adenosine A2a receptor-dependent and independent mechanisms. FASEB J. 2000;14:2065-74.

26. Sharma AK, Laubach VE, Ramos SI, Zhao Y, Stukenborg G, Linden J, et al. Adenosine A2A receptor activation on $\mathrm{CD} 4+\mathrm{T}$ lymphocytes and neutrophils attenuates lung ischemia-reperfusion injury. J Thorac Cardiovasc Surg. 2010; 139:474-82.

27. Inoue Y, Chen Y, Pauzenberger R, Hirsh MI, Junger WG. Hypertonic saline up-regulates A3 adenosine receptor expression of activated neutrophils and increases acute lung injury after sepsis. Crit Care Med. 2008;36:2569-75.

28. Machuca TN, Cypel M, Zhao Y, Grasemann H, Tavasoli F, Yeung JC, et al. The role of the endothelin-1 pathway as a biomarker for donor lung assessment in clinical ex vivo lung perfusion. J Heart Lung Transplant. 2015;34:849-57.

29. Vasanthan V, Nagendran J. Compliance trumps oxygenation: predicting quality with ex vivo lung perfusion. J Thorac Cardiovasc Surg. 2015;150:1378-9.

30. Harada M, Oto T, Otani S, Miyoshi K, Okada M, Iga N, et al. A neutrophil elastase inhibitor improves lung function during ex vivo lung perfusion. Gen Thorac Cardiovasc Surg. 2015;63:645-51. 
31. Kondo T, Chen F, Ohsumi A, Hijiya K, Motoyama H, Sowa $T$, et al. beta2-Adrenoreceptor agonist inhalation during ex vivo lung perfusion attenuates lung injury. Ann Thorac Surg. 2015;100:480-6.

32. Biancosino C, Albert M, Linder A. Acute toxicity of irinotecan in the ex-vivo isolated perfused human lung model-high-dose therapy during isolated perfusion without acute toxic lung edema. Interact Cardiovasc Thorac Surg. $2007 ; 6: 583-7$.

Key Words: ex vivo lung perfusion, lung transplantation, donation after circulatory death, porcine lung transplant model, adenosine $\mathrm{A} 2 \mathrm{~B}$ receptor antagonism

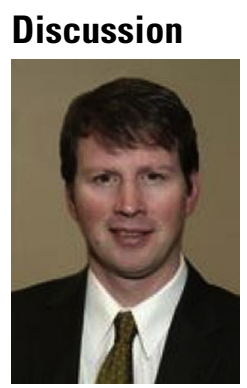

Dr Thomas K. Waddell (Toronto, Ontario, Canada). Thank you very much. I have several disclosures. I'm involved both as a consultant and as a stockholder in several companies involved in commercializing EVLP.

So I'd like to thank the Association for the opportunity to discuss this paper, and thank you, Eric, for sending me this paper in advance.

Ex vivo lung perfusion began as a technique to assess lungs after exactly this type of scenario many years ago with Dr Steen's work. It has continued to evolve and shows progress, and we're moving beyond using this technology simply as an assessment and rather to specifically recondition and recover lung injury not just from the donor injury, but as you've shown here, from the injury suffered during the agonal phase.

And the expansion of the donor pool, as you mentioned, is really going to transform lung transplantation. For example, for the audience's interest, there were in the American Heart Association 2015 estimates 326,000 people suffered out-of-hospital cardiac arrest, of whom less than $10 \%$ survived. And that means that if we simply harvested $8 \%$ of that donor pool, we could quadruple lung transplantation.

This is important work and I thought very well done. It was an excellent manuscript with very few issues. I have several questions, which I perhaps will go one by one if you don't mind.

In the introduction, you mentioned that there are proinflammatory effects as well as anti-inflammatory effects of this receptor, and I'm curious if you think that there are some things to watch out for or if this might explain some of the somewhat-divergent results you saw in your data?

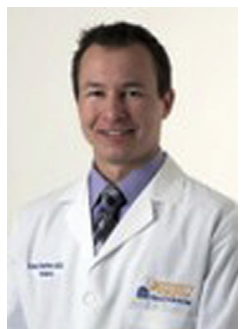

Dr Eric J. Charles (Charlottesville, Va). Thank you very much, Dr Waddell, for your thorough evaluation of the manuscript.

Adenosine is a bioactive nucleoside. It's an important part of purinergic inflammatory signaling pathways, and the data from our laboratory suggest that blocking $\mathrm{A} 2 \mathrm{~B}$ receptor signaling on both donor leukocytes and alveolar epithelial cells leads to attenuation of IR injury.

In this experiment, we used ATL802, which is 900-fold more specific for the $\mathrm{A} 2 \mathrm{~B}$ receptor as opposed to the other 3 adenosine receptors, which makes it highly selective and less likely to have adverse effects.

However, as you have mentioned, there are models that have shown that $\mathrm{A} 2 \mathrm{~B}$ receptor agonism has been anti-inflammatory. Our preliminary data showed that A2B receptor knockout mice were protected from IR injury. We believe that it's through the interaction with the donor leukocytes and the alveolar epithelial cells that we see this anti-inflammatory benefit.

Dr Waddell. Right. So that might give a rationale for donor pretreatment, I suppose.

I mean, that leads to the second question, which is that the fluid resuscitation, adrenaline requirements in particular, were quite significant. That's 2.2 liters of fluid in a small pig in only 4 hours. That's quite a massive fluid resuscitation, I would suggest, and that's in the group that was cold plus ATL802.

Is that an expected result of using that drug in the reperfusion period, that they would be so hemodynamically unstable?

Dr Charles: It was not expected, and I hypothesize not related to the drug therapy. There was one animal that was particularly unstable in group Cold + ATL802 and required significant amounts of both fluid and epinephrine during the reperfusion period. The values from that animal contributed to the mean value for that group being much higher than expected.

Dr Waddell. It wasn't your first pig lung transplant, was it?

Okay. So then the last question is really to try and address the discrepancy between the effect on compliance and the effect on oxygenation. And in particular, and I didn't talk to you about this before, but the effect on oxygenation, it seems that there is quite a wide variability in the EVLP plus ATL802 group where some animals did very well and some animals did very poorly.

So what are we to make of that? Should we begin using this drug in our clinical programs tomorrow? Thank you very much.

Dr Charles. Thank you for your questions. Clinical recommendations have started to favor compliance as a more accurate predictor of lung function as opposed to $\mathrm{PaO}_{2} / \mathrm{FiO}_{2}$ ratios due to the variability in measuring oxygenation capacity. I would hesitate to begin using this drug in our clinical programs, as there is still a lot of preliminary laboratory work that needs to be done.

However, we do need to translate our findings with these drug compounds into human lung studies to account for the inherent variability between pig and human lungs. This is something that we are starting to do at the University of 
Virginia, but we plan to use an adenosine-receptor compound that we have a little bit more experience with first.

Dr Andrew C. Chang (Ann Arbor, Mich). Have you explored whether this drug is effective in models of aspiration? Oftentimes donors are declined for use because of aspiration or other acute proinflammatory processes.

Your group has studied A2A in transplantation quite well. Can you comment whether A2A-directed treatment can reverse such proinflammatory effects in addition to the standard procurement problems? Thank you.
Dr Charles. Thank you for your question Dr Chang; that's a great thought. We have not yet looked at whether these drugs can reverse the detrimental effects of aspiration.

However, there are some preliminary data from other groups looking at targeting adenosine receptors to treat bronchospasm and asthma. There could be a benefit there, which may allow for some additional rehabilitation and improve our ability to use lungs after aspiration. 